\title{
Simulation in cardiothoracic surgical training: Where do we stand?
}

\author{
Kanika Trehan, MS, Clinton D. Kemp, MD, and Stephen C. Yang, MD
}

\begin{abstract}
Objectives: Simulation may reduce the risks associated with the complex operations of cardiothoracic surgery and help create a more efficient, thorough, and uniform curriculum for cardiothoracic surgery fellowship. Here, we review the current status of simulation in cardiothoracic surgical training and provide an overview of all simulation models applicable to cardiothoracic surgery that have been published to date.
\end{abstract}

Methods: We completed a comprehensive search of all publications pertaining to simulation of cardiothoracic surgical procedures by using PubMed.

Results: Numerous cardiothoracic surgical simulators at various stages of development, assessment, and commercial manufacturing have been published to date. There is currently a predominance of models simulating coronary artery bypass grafting and bronchoscopy and a relative paucity of simulators of open pulmonary and esophageal procedures. Despite the wide range of simulators available, few models have been formally assessed for validity and educational value.

Conclusions: Surgical simulation is becoming an increasingly important educational tool in training cardiothoracic surgeons. Our next steps forward will be to develop an objective, standardized way to assess surgical simulation training compared with the current apprenticeship model. (J Thorac Cardiovasc Surg 2014;147:18-24)

Supplemental material is available online.

Seven years ago, the Thoracic Surgery Foundation for Research and Education held the Visioning Simulation Conference (VSC) to accelerate the implementation of simulation in cardiothoracic (CT) surgery. ${ }^{1}$ Discussion about technologic, financial, and political barriers to the implementation of simulation in CT surgery led to numerous advances, and this report summarizes much of the published data on simulation in cardiac, general thoracic, and endovascular surgery to date.

\section{HISTORY OF SIMULATION IN SURGICAL TRAINING}

Modern surgical simulation dates back to the 1800 s when surgeons practiced procedures on cadavers and animals. ${ }^{2}$ Today, the scarce resources, ethical questions, and anatomic inaccuracy of this approach leave us in search of better options. Surgeons began using the first artificial simulators

From the Division of Thoracic Surgery, Department of Surgery, The Johns Hopkins Medical Institutions, Baltimore, Md.

Disclosures: Authors have nothing to disclose with regard to commercial support.

Received for publication Feb 11, 2013; revisions received April 22, 2013; accepted for publication Sept 24, 2013

Address for reprints: Stephen C. Yang, MD, The Arthur B. and Patricia B. Modell Professor of Thoracic Surgery, Chief of Thoracic Surgery, Professor of Surgery and Oncology, The Johns Hopkins Medical Institutions, 600 N. Wolfe St, Blalock 240, Baltimore, MD 21287 (E-mail: syang@jhmi.edu).

$0022-5223 / \$ 36.00$

Copyright (c) 2014 by The American Association for Thoracic Surgery

http://dx.doi.org/10.1016/j.jtcvs.2013.09.007 only a few decades ago, and within the last several years the Accreditation Council for Graduate Medical Education and the American College of Surgeons have declared strong support for the use of simulation in surgical training, and such programs as the Fundamentals of Laparoscopic Surgery are now mandated for general surgeons to obtain board certification. ${ }^{3}$ These events mark the beginning of a potential revolution in surgical education.

\section{VALUE OF SIMULATION IN CARDIOTHORACIC SURGERY}

CT surgery training can benefit greatly from simulation considering the high risks and broad range of open, minimally invasive, and endovascular techniques that trainees are expected to learn. ${ }^{4}$ Moreover, as the incidence of cardiovascular and thoracic disease grows, the $\mathrm{CT}$ surgical workforce is projected to decline by $50 \%$ over the next 10 years, creating a tremendous demand for well-trained CT surgeons. ${ }^{5}$ Simulation may help by increasing learning opportunities for residents, eliminating costs of cadaver and animal use, decreasing the use of operating room (OR) time at teaching institutions, and integrating new technologies into patient care more smoothly. ${ }^{6}$ Simulation also may lay the foundations for uniform certification and assessment standards for graduating CT fellows. ${ }^{1}$ The 2007 VSC and the establishment of the Thoracic Surgery Directors Association Boot Camp in 2008 have been important recent events to spur advancement of CT surgery simulation. ${ }^{7}$ In addition, the Joint Council for Thoracic Surgery Education is currently developing a simulation curriculum with specified modules and assessment tools specific for training programs. ${ }^{8}$ 

Abbreviations and Acronyms
$\mathrm{CAB}=$ coronary artery bypass
$\mathrm{CPB}=$ cardiopulmonary bypass
$\mathrm{CT}=$ cardiothoracic
HPS = human performance simulator
$\mathrm{OR}=$ operating room
SBM $=$ simple bench model
VATS $=$ video-assisted thoracoscopic surgery
VRS = virtual reality simulator
VSC $=$ Visioning Simulation Conference

\section{TYPES OF SIMULATION TECHNOLOGIES}

Three broad categories of surgical simulators include the simple bench model (SBM), virtual reality simulator (VRS), and human performance simulator (HPS) (Table 1). SBMs are "partial-task" tools that simulate a small component of a larger operation. They may be synthetic (eg, rubber vessels to simulate coronary anastomosis) or consist of biological tissue (eg, porcine or bovine organs to practice valve suturing). Use of biological tissues in many of these models decreases cost- and time-efficiency and may not accurately mimic human anatomy; however, SBMs are generally inexpensive and easily available to most centers and trainees. Thus, SBMs are best used as an introduction to an operation before learning in a more realistic environment. ${ }^{9}$

The VRS is computer-based and often lacks a physical component. Thoracoscopic or laparoscopic tools are used to manipulate virtual organs, making virtual reality simulation readily reusable with little maintenance, an advantage that can offset high initial costs. With sophisticated programming, these models can present broad clinical variation, interactively respond to the user, and independently provide performance assessment and feedback. The biggest disadvantage of this technology is the use of a 2-dimensional computer screen that compromises depth perception and tactile sensation of the real 3-dimensional environment; however, because these are also the limitations of video-assisted thoracoscopic surgery (VATS) and laparoscopic surgery, VRS is ideal for learning such procedures. ${ }^{6}$

The HPS is a high-technology system that fuses an elaborate physical component with a computer interface. These systems typically simulate the entire OR environment and are used for both individual and team training of an operation from start to finish. ${ }^{9}$ This is particularly useful for simulating CT crisis management, which involves attention to a complex interplay of many real-life details in a high-stakes environment. ${ }^{10-12}$ Like VRS, HPS can include patient variation and capabilities for assessment and feedback. However, use of biological tissue and numerous intricate parts increase resource use and maintenance time.

\section{CURRENT SIMULATORS IN CARDIOTHORACIC SURGERY}

Discussions at the VSC identified several areas in need of simulation, including cardiopulmonary bypass (CPB), coronary artery bypass (CAB), VATS, open lobectomy, and endovascular procedures. Table 2 contains a comprehensive list of CT surgery simulators published to date.

\section{CARDIOVASCULAR \\ Cardiopulmonary Bypass}

The Orpheus Cardiopulmonary Bypass Simulation System (ULCO Technologies, Marrickville, Australia) trains a team of surgeons, anesthesiologists, perfusionists, and OR nurses together in performing CPB (Figure E1). It includes an entire OR with a heart-lung machine, heater/ cooler, patient monitor, anesthetic machine, and artificial patient substitute. The Orpheus can be connected to a monitoring system to display the electrocardiograms, arterial waveform, temperature, blood gas, and coagulation parameters based on pre-programmed patient cases or customized cases designed by an instructor. Simulation of drug administration, as well as equipment malfunctioning, alters patient parameters in real-time. ${ }^{13}$ Burkhart and colleagues ${ }^{14}$ studied this model as an educational tool and found significant improvement in confidence and knowledge, and participants preferred this learning method over classroom and clinical-based learning. The Turkmen simulator is a similar model designed to train perfusionists in the operation of a heart-lung machine. ${ }^{15}$

A less-expensive simulator for CPB is the Hicks perfused nonbeating heart, composed of a porcine heart with the intact thoracic aorta. The aorta is perfused with a pressurized bag of saline to mimic blood flow and leakage, and the organ bloc is placed in an inexpensive plastic container and draped to mimic the thoracic cavity. ${ }^{16,17}$

\section{Coronary Artery Bypass}

The Ramphal Cardiac Surgery Simulator is a perfused, beating heart simulator used most extensively for $\mathrm{CAB}$ (Figure E2). ${ }^{18}$ It includes a porcine heart with the right and left ventricles filled with balloons that are connected to a computer-controlled pneumatic pump, allowing their inflation to simulate pulsation of the heart. The rate and force of contraction can vary in response to handling through sensors connected to the computer, and blood pressure and core temperature also change in response to stimuli. Artificial blood perfuses the entire system, including the coronary arteries and veins, atria, and ventricles via a perfusion line connected to a roller pump. The heart is placed in a realistically pigmented well in the anterior chest wall of a life-sized mannequin to simulate a standard median sternotomy.

Early beating-heart SBMs, such as the Zurich HeartTrainer and Izzat off-pump CAB model, paved the way 
TABLE 1. Categories of surgical simulators

\begin{tabular}{|c|c|c|c|c|}
\hline $\begin{array}{l}\text { Type of } \\
\text { simulator }\end{array}$ & Description & Advantages & Disadvantages & Example \\
\hline SBM & $\begin{array}{l}\text { Simple physical model for basic } \\
\text { tasks }\end{array}$ & $\begin{array}{l}\text { Inexpensive, allows repetition of } \\
1 \text { task }\end{array}$ & Incomplete surgical experience & $\begin{array}{l}\text { The Chamberlain Group - Heart } \\
\text { Case }^{22}\end{array}$ \\
\hline VRS & $\begin{array}{l}\text { Computer-based simulation for } \\
\text { minimally invasive surgery }\end{array}$ & $\begin{array}{l}\text { Can offer clinical variation and } \\
\text { user assessment, little setup or } \\
\text { downtime }\end{array}$ & $\begin{array}{l}\text { Expensive, does not simulate } \\
\text { open surgery }\end{array}$ & $\begin{array}{l}\text { CAE Healthcare (Sarasota, Fla) - } \\
\text { AccuTouch (CAE Healthcare) }{ }^{28}\end{array}$ \\
\hline HPS & $\begin{array}{l}\text { Simulates most aspects of the } \\
\text { surgery and environment using } \\
\text { computer and physical interfaces }\end{array}$ & $\begin{array}{l}\text { Can offer clinical variation and } \\
\text { user assessment, capacity for } \\
\text { team training }\end{array}$ & $\begin{array}{l}\text { Expensive, may involve } \\
\text { extensive setup and downtime }\end{array}$ & $\begin{array}{l}\text { Ramphal - Cardiac Surgery } \\
\text { Simulator }^{14}\end{array}$ \\
\hline
\end{tabular}

HPS, Human performance simulator; SBM, simple bench model; VRS, virtual reality simulator.

for the most recent developments in beating heart models. ${ }^{19,20}$ One such model is the Chamberlain beating heart trainer described by The Chamberlain Group. ${ }^{21}$ This sutureable rubber model has an anatomically realistic appearance and is able to contract at different speeds and rhythms to serve as a high-fidelity SBM. Another model, the EBM Beating Heart (Engineering Based Medicine, Tokyo, Japan) beating heart, ${ }^{22}$ consists of a vibrating platform that can be used in conjunction with a simple nonbeating vessel or heart model, such as the porcine heart described by Fann and colleagues. ${ }^{23,24}$

\section{Other Cardiac Procedures}

Although CPB and CAB represent the majority of CT surgery simulators published to date, a few models have been developed for other important procedures as well. The Nakao Cardiac Model is a haptically enabled VRS that provides interactive visualization of a 3-dimensional beating heart for practicing surgical palpation. ${ }^{25}$ Berlage

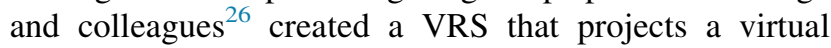
beating heart, ribs, and chest surface onto a patient's unique thoracic CT scans. One can adjust the patient's position and use virtual instruments to practice placing ports in optimal locations. ${ }^{26}$ Joyce and colleagues ${ }^{27}$ used a silicone Mitral Valve Model from The Chamberlain Group (Great Barrington, Mass) to demonstrate improved resident performance of simulated mitral valve surgery through practice. ${ }^{27}$ Tavlasoglu and colleagues ${ }^{28}$ developed an SBM for mitral valve repair using a bovine heart mounted on a stable platform with atrial retractors. The Chamberlain Heart Case (The Chamberlain Group) is an SBM that can be adjusted to simulate multiple cardiac procedures, including $\mathrm{CAB}$ and aortic graft anastomosis, and valve procedures. ${ }^{29}$

\section{GENERAL THORACIC}

\section{Video-Assisted Thoracoscopic Surgery Resection}

Solomon and colleagues ${ }^{30}$ developed a VRS for VATS right upper lobectomy. A computer screen projects an OR view of a patient in the left lateral decubitus position, which transitions to an internal view of the lung, hilum, and mediastinum on thoracoscope placement into an artificial chest wall. A haptic feedback device controls the movement of virtual instruments to mimic the physical constraints of VATS. Dissecting tools and a stapling device are used for dissection, division, and ligation of tissue. Current models include 3 different pulmonary vein variations, 2 pulmonary artery variations, and the presence or absence of pleural metastatic disease. This simulator tracks performance, identifies surgical errors, and provides instructive questions on anatomy, pathophysiology, and surgical intervention.

The Fukuoka University VATS simulator developed by Iwasaki and colleagues ${ }^{31}$ is an HPS for VATS right upper lobectomy. The plastic hemithorax includes a detachable wall with pre-made incisions, ribs, inflatable right lung, plastic bronchus, and artificial blood vessels. The right upper lobe of the lung is separate from the middle and lower lobes, allowing easy removal. Artificial blood perfuses the vessels from 0 to $6400 \mathrm{~mL} / \mathrm{min}$ with pulsations set to 0 to 80 beats/min, enabling massive pulsatile bleeding on injury to blood vessels.

Two low-cost bench models for VATS resection also have been published. Tesche and colleagues ${ }^{32}$ used porcine lungs injected with silicone globules to represent tumors. The lungs were positioned within a hemithorax containing 3 openings for the thoracoscope and VATS instruments. Fann and colleagues ${ }^{33}$ created a similar porcine lungbased model, and Meyerson and colleagues ${ }^{34}$ simulated VATS lobectomy using a porcine heart and lung block covered with an inexpensive rubber box in which holes were cut for insertion of surgical equipment.

\section{Open Lobectomy}

Of open lobectomy simulators, only SBMs have been published. Carter and colleagues ${ }^{35}$ developed an artificial torso with a posterolateral thoracotomy incision encasing a single bovine lung to simulate the appearance of a deflated lung. The model was used to practice knot tying, suturing, and pulmonary resection. The second model, developed by Tesche and colleagues, ${ }^{32}$ consists of a life-sized artificial hemithorax with a posterolateral thoracotomy incision providing access to a porcine heart and lung. Pulmonary vessels are perfused with synthetic blood, enabling practice 
TABLE 2. Cardiothoracic surgery simulators

\begin{tabular}{|c|c|c|c|c|c|c|}
\hline Procedure & Simulator and reference & Type & $\begin{array}{c}\text { Animal } \\
\text { tissue }\end{array}$ & $\begin{array}{c}\text { Patient } \\
\text { variability }\end{array}$ & Interactive* & $\begin{array}{c}\text { Independent } \\
\text { assessment } \\
\text { capability } \dagger \\
\end{array}$ \\
\hline \multicolumn{7}{|l|}{ Cardiovascular } \\
\hline \multirow[t]{4}{*}{$\mathrm{CPB}$} & ULCO Technologies (Marrickville, Australia) - Orpheus ${ }^{13} \ddagger$ & HPS & No & Yes & Yes & No \\
\hline & Turkmen and colleagues - Perfusion Training Simulator ${ }^{15}$ & HPS & No & Yes & Yes & No \\
\hline & Hicks and colleagues - Perfused Nonbeating Heart Model ${ }^{16} \ddagger$ & SBM & Yes & No & No & No \\
\hline & & SBM & Yes & No & No & No \\
\hline \multirow[t]{8}{*}{ CABG } & Ramphal and colleagues - Cardiac Surgery Simulator ${ }^{18} \ddagger$ & HPS & Yes & Yes & Yes & No \\
\hline & Reuthebuch and colleagues - Zurich Heart-Trainer ${ }^{19}$ & HPS & No & Yes & No & No \\
\hline & $\begin{array}{l}\text { The Chamberlain Group (Great Barrington, Mass) - Chamberlain } \\
\text { Beating Heart Model }{ }^{21} \ddagger\end{array}$ & SBM & No & Yes & No & No \\
\hline & Engineering Based Medicine (Tokyo, Japan) - Beating Heart Model ${ }^{22}$ & SBM & No & No & No & No \\
\hline & Izzat and colleagues - Beating Heart Platform ${ }^{20}$ & SBM & No & Yes & No & No \\
\hline & Fann and colleagues - Anastomosis Task Station ${ }^{23} \ddagger$ & SBM & No & No & No & No \\
\hline & Fann and colleagues - Beating Heart Model $^{23} \ddagger$ & SBM & Yes & No & No & No \\
\hline & Fann and colleagues - Porcine Heart Model ${ }^{24} \underset{\ddagger}{\dagger}$ & SBM & Yes & No & No & No \\
\hline \multirow[t]{5}{*}{ Other cardiac } & Nakao and colleagues - Virtual Reality Cardiac Model ${ }^{25}$ & VRS & No & No & No & No \\
\hline & $\begin{array}{l}\text { Berlage and colleagues - Minimally Invasive Cardiac Surgery } \\
\text { Simulator } \\
{ }^{26}\end{array}$ & VRS & No & Yes & No & No \\
\hline & Joyce and colleagues - Mitral Valve Model $^{27} \ddagger$ & SBM & No & No & No & No \\
\hline & Tavlasoglu and colleagues - Mitral Valve Model ${ }^{28}$ & SBM & Yes & No & No & No \\
\hline & The Chamberlain Group - Heart Case ${ }^{29}$ & SBM & No & No & No & No \\
\hline \multicolumn{7}{|l|}{ General thoracic } \\
\hline \multirow[t]{5}{*}{ VATS resection } & Solomon and colleagues - Virtual Reality Lobectomy Simulator ${ }^{30}$ & VRS & No & Yes & No & Yes \\
\hline & Iwasaki and colleagues - Fukuoka University VATS Simulator ${ }^{31} \ddagger$ & HPS & No & No & No & No \\
\hline & $\begin{array}{l}\text { Tesche and colleagues - Silicone Tumor Resection from Porcine } \\
\text { Lung }{ }^{32} \ddagger\end{array}$ & SBM & Yes & Yes & No & No \\
\hline & Fann and colleagues - Porcine Lung VATS Simulator ${ }^{33} \ddagger$ & SBM & Yes & No & No & No \\
\hline & Meyerson and colleagues - Rubber Box Lobectomy Simulator ${ }^{34} \ddagger$ & SBM & Yes & No & No & No \\
\hline \multirow[t]{3}{*}{ Open pulmonary } & Carter and Marshall - Bovine Lung in Artificial Torso ${ }^{35} \ddagger$ & SBM & Yes & No & No & No \\
\hline & Tesche and colleagues - Porcine Lung in Artificial Torso ${ }^{32} \ddagger$ & SBM & Yes & No & No & No \\
\hline & Fann and colleagues - Porcine Lung Sleeve Resection Model ${ }^{33} \ddagger$ & SBM & Yes & No & No & No \\
\hline \multirow[t]{9}{*}{ Bronchoscopy } & CAE Healthcare (Sarasota, Fla) - AccuTouch ${ }^{36} \ddagger, \S$ & VRS & No & Yes & Yes & Yes \\
\hline & Simbionix (Cleveland, Ohio) - GI-Bronch Mentor ${ }^{37}$ & VRS & No & Yes & Yes & Yes \\
\hline & $\begin{array}{l}\text { Immersion Corporation (San Jose, Calif) - PreOp Endoscopic } \\
\text { Simulator }{ }^{39} \ddagger, \S\end{array}$ & VRS & No & Yes & Yes & Yes \\
\hline & Chen and colleagues - Computer-Based Bronchoscopy Simulator ${ }^{38} \ddagger$ & VRS & No & Yes & Yes & Yes \\
\hline & CLA (Coburg, Germany) - Broncho Boy ${ }^{36}$ & SBM & No & No & No & No \\
\hline & Laederal (Stavanger, Norway) - Airway Management System ${ }^{36}$ & SBM & No & No & No & No \\
\hline & Trucorp (Belfast, Northern Ireland) - AirSim ${ }^{40} \ddagger$ & SBM & No & Yes & No & No \\
\hline & $\begin{array}{l}\text { Di Domenico and colleagues - Paper Mache Bronchoscopy } \\
\text { Simulator }\end{array}$ & SBM & No & No & No & No \\
\hline & $\begin{array}{l}\text { Immersion Corp (San Jose, Calif) - Endobronchial Ultrasound } \\
\text { Simulator }^{42}\end{array}$ & VRS & No & Yes & Yes & No \\
\hline \multirow[t]{5}{*}{ Esophageal } & Simbionix (Cleveland, Ohio) - GI-Mentor ${ }^{43} \ddagger$ & VRS & No & Yes & Yes & Yes \\
\hline & Neumann and colleagues - Erlangen Endo-Trainer ${ }^{44} \S$ & HPS & Yes & Yes & No & No \\
\hline & Choi and colleagues - Virtual Reality Esophagus Model ${ }^{45}$ & VRS & No & No & No & No \\
\hline & Fann and colleagues - Esophagectomy Model ${ }^{33} \ddagger$ & SBM & Yes & No & No & No \\
\hline & Trehan and colleagues - THE GooseMan ${ }^{46}$ & SBM & Yes & No & No & No \\
\hline \multirow[t]{6}{*}{ Other thoracic } & CIMIT (Boston, Mass) - VIRGIL Chest Trauma Training System ${ }^{47}$ & HPS & No & Yes & No & Yes \\
\hline & Simulab Corporation (Seattle, Wash) - TraumaMan ${ }^{47} \ddagger, \S$ & HPS & No & No & No & No \\
\hline & METI - iSTAN (CAE Healthcare) $)^{48}$ & HPS & No & Yes & Yes & No \\
\hline & Simulation (Burnsville, Minn) - Chest Drain Simulator ${ }^{49}$ & SBM & No & No & No & No \\
\hline & Carter and colleagues - Multipurpose Simulator ${ }^{50_{\ddagger}}$ & SBM & Yes & Yes & No & No \\
\hline & Marshall and colleagues - Chest Wall Tumor ${ }^{51} \ddagger$ & SBM & Yes & Yes & No & No \\
\hline
\end{tabular}


TABLE 2. Continued

\begin{tabular}{|c|c|c|c|c|c|c|}
\hline Procedure & Simulator and reference & Type & $\begin{array}{c}\text { Animal } \\
\text { tissue }\end{array}$ & $\begin{array}{c}\text { Patient } \\
\text { variability }\end{array}$ & Interactive* & $\begin{array}{c}\text { Independent } \\
\text { assessment } \\
\text { capability } \dagger\end{array}$ \\
\hline \multirow{3}{*}{\multicolumn{7}{|c|}{$\begin{array}{l}\text { Naicker and colleagues - Resin-Porcine Thorax } \operatorname{Model}^{52} \S \\
\text { Fann and colleagues - Tracheostomy Model }{ }^{33} \ddagger\end{array}$}} \\
\hline & & & & & & \\
\hline & & & & & & \\
\hline \multirow{4}{*}{$\begin{array}{r}\text { Endovascular } \\
\text { procedures }\end{array}$} & Simbionix - ANGIOmentor ${ }^{364_{\dagger}}$ & HPS & No & Yes & Yes & Yes \\
\hline & Simbionix - PROcedure ${ }^{53} \ddagger$ & HPS & No & Yes & Yes & Yes \\
\hline & Mentice (Evanston, Ill) - Procedicus VIST ${ }^{54} \ddagger$ & HPS & No & Yes & Yes & Yes \\
\hline & Medical Simulation Corporation (Denver, Colo) - SimSuite $^{55} \ddagger$ & HPS & No & Yes & Yes & Yes \\
\hline
\end{tabular}

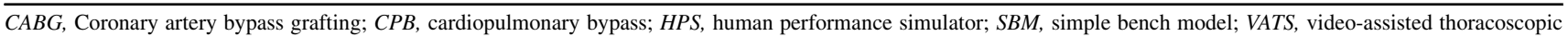
surgery; $V R S$, virtual reality simulator. *Interactive is defined as the ability to vary responses on the basis of different actions taken by the user. $†$ Independent assessment capability is defined by ability of the simulator to provide immediate performance feedback without the supervision of an instructor. $\ddagger$ Data on educational value have been published. Educational value is defined as having the ability to educate trainees reliably to a defined level of proficiency. $\S$ Data on validity have been published. Validity is defined as resembling the real task as closely as necessary for teaching purposes.

of vessel isolation and ligation, removal of various anatomic segments of the lungs, and surgical stapling techniques. Fann and colleagues ${ }^{33}$ created a similar model with a porcine heart-lung block for practicing sleeve resection.

\section{Bronchoscopy}

Bronchoscopy is the most widely simulated general thoracic surgical procedure. The AccuTouch Flexible Bronchoscopy Simulator (CAE Healthcare, Sarasota, Fla) is a VRS with a physical component consisting of a face, with an opening in 1 nare for insertion of a fiberoptic bronchoscope. As the scope advances, it provides realistic force feedback while a computer displays the endobronchial anatomy. ${ }^{32,36}$ The tissue appears to deform, contract, and bleed realistically on collision. In addition, the artificial patient coughs, provides verbal cues, and changes vital signs in response to bronchoalveolar lavage, endobronchial biopsy, transbronchial biopsy, and transbronchial needle aspiration. The system also provides instruction on performing procedures, helps identify lesions, offers anatomy tutorials, and assesses overall performance. The GI-Bronch Mentor (Simbionix, Cleveland, Ohio) is similar to the AccuTouch system, but it includes the use of an authentic bronchoscope, the ability to insert the scope through the oral or nasal passageways, and can present a broader range of pathologies and clinical situations. ${ }^{37}$

Less-expensive options include the PreOp Endoscopic Simulator (Immersion Corporation, San Jose, Calif) and the Computer-Based Bronchoscopy Simulator by Chen and colleagues, ${ }^{38}$ both of which have many of the same capabilities as the AccuTouch (CAE Healthcare) and GIBronch Mentor (Simbionix). ${ }^{39}$ The least expensive bronchoscopy simulators include the silicone CLA Broncho Boy (CLA, Coburg, Germany), Laederal Airway Management System (Laederal, Savanger, Norway), and AirSim (Trucorp, Belfast, Northern Ireland), which allow for rigid and flexible bronchoscopy using a sophisticated physical model. ${ }^{36,40}$ Di Domenico and colleagues ${ }^{41}$ made a paper mache bronchoscopy simulator for approximately $\$ 20$. The Immersion Corporation recently released a simulator for endobronchial ultrasound that incorporates haptic feedback. ${ }^{42}$

\section{Esophageal Procedures}

The majority of esophageal surgery simulators to date teach endoscopic procedures using VR. The GI-Mentor developed by Simbionix includes an endoscope with motion sensors that integrate visual output and force-feedback as it advances through a mannequin. The instructor can assign specific patient cases and send messages to the student in real time. ${ }^{43}$ The Erlangen Endo-Trainer uses a porcine esophagus, stomach, duodenum, liver, gall bladder, and bile duct system with an artificial human torso for endoscopic techniques. It can simulate bleeding, artificial bile duct stones, polyps, tumors, and varicies. ${ }^{44}$ A model developed by Choi and colleagues ${ }^{45}$ includes an artificial esophagus with haptics for handling and cutting, as well as a computer screen that depicts tissue manipulation. Most recently, Fann and colleagues ${ }^{33}$ and Trehan and colleagues ${ }^{46}$ developed porcine organ-based SBMs for esophagectomy.

\section{Other Thoracic Procedures}

Other basic thoracic procedures also have been simulated. The VIRGIL Chest Trauma Training System (CIMIT, Boston, Mass) simulates chest tube insertion into a mannequin with a computer that displays internal positioning. It presents variable internal anatomy and assesses the user's performance. ${ }^{47}$ TraumaMan (Simulab Corporation, Seattle, Wash) also simulates chest tube insertion, along with pericardiocentesis and needle decompression. The artificial thorax includes a chest wall with a clavicle, sternum, ribs and intercostal muscles, inflatable lungs, and a heart and pericardium that can be filled with simulated bodily fluids for needle decompression. The iSTAN (METI; CAE Healthcare) simulates chest tube insertion, defibrillation, 
catheterization, and needle decompression. This wireless robot can blink, drool, cry, sweat, breathe, and bleed in response to interventions or simulated emergencies. ${ }^{48}$ The Chest Drain Simulator (Simulation, Burnsville, Minn) is a simpler and less-expensive chest tube insertion model with realistic mechanical properties. ${ }^{49}$

Inexpensive SBMs for basic thoracic procedures include Carter and colleagues' Multipurpose Simulator ${ }^{50}$ which is made of porcine ribs and a bag of fluid secured inside a mannequin for practicing thoracentesis. Marshall and colleagues ${ }^{51}$ developed a model for removing chest wall tumors by injecting insulating foam sealant into the intercostal space of porcine ribs, and Naicker and colleagues ${ }^{52}$ created a simulator for chest drain insertion using a thorax made of resin and porcine ribs. Fann and colleagues $^{33}$ describe a porcine tracheal-esophageal block used to simulate tracheal resection.

\section{ENDOVASCULAR}

The ANGIOmentor (Simbionix) is a virtual patient used for the placement of carotid stents, guidewires, catheters, balloons, and electrode leads, as well as for aortic valve replacement. Real-time fluoroscopy images and force feedback based on unique patient cases are available. Electrocardiography, blood pressure, aortic pressure, heart rate, oxygen saturation, and neurologic findings are presented throughout the simulation and change in response to intervention. ${ }^{47}$ The PROcedure, a similar model from Simbionix, presents a 3-dimensional anatomic model of a specific patient's vasculature to allow "surgical rehearsal." ${ }^{53}$ The Procedicus VIST (Mentice Medical Simulations, Evanston, Ill) and SimSuite (Medical Simulation Corporation, Denver, Colo) are other virtual patients for vascular interventions with similar capabilities. ${ }^{54,55}$

\section{Future Directions}

Simulation may reduce risks associated with the complex operations of CT surgery and help create a more efficient, thorough, and uniform curriculum for CT surgery fellowship. Yet the lack of financial and political support, as well as questions about Medicare funding for fellows as clinical responsibilities decrease with simulation, preclude its wide scale use. To provide concrete data in support of this training approach, we must develop an objective standardized way to assess surgical simulation training compared with the current apprenticeship model. This is difficult to do, and currently most CT simulators have not been formally assessed for validity or educational value (Table 2).

Various groups have independently assessed simulationbased training in CT surgery using different methods that may guide the development of a universal assessment strategy. Cristancho and colleagues ${ }^{56}$ had a group of expert physicians agree on a deconstruction of the $\mathrm{CAB}$ procedure into key teachable components that were simulated for residents who were then evaluated on the basis of checklists of important tasks. Konge and colleagues ${ }^{57}$ reported a method for developing a thorough assessment tool for VATS performance by asking expert physicians to agree on the most important parameters to assess with a 10-question Likert-based survey. Tong and colleagues ${ }^{58}$ looked at the ability of their thoracoscopic lobectomy model to differentiate among experienced, intermediate, and novice residents on the basis of ability of the participant to complete the simulation in a timely manner and also asked more experienced residents to rate the similarity of the simulation to the actual operation on a 5-point Likert scale. Price and colleagues ${ }^{59}$ performed a randomized controlled trial in which surgical residents were assigned to expert-guided simulation training of vascular anastomosis alone or in combination with self-directed practice for 2 additional weeks and found significantly improved performance in the second group based on the Objective Structured Assessment of Technical Skill, as well as end-product evaluation and time to completion. Finally, Fann and colleagues ${ }^{33}$ reported on the comprehensive experience of 12 senior CT surgeons who evaluated numerous cardiac and thoracic simulators in development using a 3-point scale questionnaire on realism, importance of emphasized skills, and value as a training tool in addition to holding a discussion for each model by the evaluators.

\section{CONCLUSIONS}

All of these studies have shown evidence for the unmistakable value of simulation in CT surgery training; however, most educators also agree that there are important limitations to simulation-based training. As medical understanding advances and new techniques are developed, original models may become outdated and require costly upgrades or complete replacement. Also, simulation may never mimic the feel of living human tissue, the complexity of human physiology, or all the psychosocial nuances of real patient care. Thus, simulation is not meant to eliminate the need for genuine patient interaction and real OR experience, but to serve as an important adjunct for safer transition to independent patient care and continued practice.

\section{References}

1. Carpenter AJ, Yang SC, Uhlig PN, Colson YL. Envisioning simulation in the
future of thoracic surgical education. J Thorac Cardiovasc Surg. 2008;135:
477-84.
2. Anastakis DJ, Regehr G, Reznick RK, Cusimano M, Murnaghan J, Brown M,
et al. Assessment of technical skills transfer from the bench training model to
the human model. Am J Surg. 1999;177:167-70.
3. Roberts KE, Bell RL, Duffy AJ. Evolution of surgical skills training. World J
Gastroenterol. 2006;12:3219-24.
4. Carter BN. The fruition of Halsted's concept of surgical training. Surgery. 1952;
32:518-27.
5. Grover A, Gorman K, Dall TM, Jonas R, Lytle B, Shemin R, et al. Shortage of
cardiothoracic surgeons is likely by 2020. Circulation. 2009;120:488-94. 
6. Scott DJ, Bergen PC, Rege RV, Laycock R, Tesfay ST, Valentine RJ, et al. Laparoscopic training on bench models: better and more cost effective than operating room experience? J Am Coll Surg. 2000;191:272-83.

7. Hicks GL Jr, Brown JW, Calhoon JH, Merrill WH. You never know unless you try. J Thorac Cardiovasc Surg. 2008;136:814-5.

8. Verrier ED. Joint Council on Thoracic Surgical Education: an investment in our future. J Thorac Cardiovasc Surg. 2011;141:318-21.

9. Reznick RK, MacRae H. Teaching surgical skills-changes in the wind. $N$ Engl J Med. 2006;355:2664-9.

10. Bruppacher HR, Alam SK, LeBlanc VR, Latter D, Naik VN, Savoldelli GL, et al. Simulation-based training improves physicians' performance in patient care in high-stakes clinical setting of cardiac surgery. Anesthesiology. 2010;112:985-92.

11. Stevens LM, Cooper JB, Raemer DB, Schneider RC, Frankel AS, Berry WR, et al. Educational program in crisis management for cardiac surgery teams including high realism simulation. J Thorac Cardiovasc Surg. 2012;144:17-24.

12. Burkhart HM, Riley JB, Lynch JJ, Suri RM, Greason KL, Joyce LD, et al. Simulation-based postcardiotomy extracorporeal membrane oxygenation crisis training for thoracic surgery residents. Ann Thorac Surg. 2013;95:901-6.

13. Morris RW, Pybus DA. "Orpheus" cardiopulmonary bypass simulation system. J Extra Corpor Technol. 2007;39:228-33.

14. Burkhart HM, Riley JB, Hendrickson SE, Glenn GF, Lynch JJ, Arnold JJ, et al. The successful application of simulation-based training in thoracic surgery residency. J Thorac Cardiovasc Surg. 2010;139:707-12.

15. Turkmen A, Rosinski D, Noyes N. A simulator for perfusion training. Perfusion. 2007;22:397-400.

16. Hicks GL Jr, Gangemi J, Angona RE Jr, Ramphal PS, Feins RH, Fann JI. Cardiopulmonary bypass simulation at the Boot Camp. J Thorac Cardiovasc Surg. 2011;141:284-92.

17. Schiralli MP, Hicks GL, Angona RE, Gangemi JJ. An inexpensive cardiac bypass cannulation simulator: facing challenges of modern training. Ann Thorac Surg. 2010;89:2056-7.

18. Ramphal PS, Coore DN, Craven MP, Forbes NF, Newman SM, Coye AA, et al. A high fidelity tissue-based cardiac surgical simulator. Eur J Cardiothorac Surg. 2005;27:910-6

19. Reuthebuch O, Lang A, Groscurth P, Lachat M, Turina M, Zund G. Advanced training model for beating heart coronary artery surgery: the Zurich heart-trainer. Eur J Cardiothorac Surg. 2002;22:244-8.

20. Izzat MB, El-Zufari MH, Yim AP. Training model for "beating-heart" coronary artery anastomoses. Ann Thorac Surg. 1998;66:580-1.

21. The Chamberlain Group. Beating heart with great vessels. Available at: http://www.thecgroup.com/product/cardiothoracic/heart/beating-heart-with-gre at-vessels-2. Accessed November 9, 2013.

22. Engineering Based Medicine. Organoid You can coronary artery silicone model. Available at: http://www.ebm.vc/products/youcan_beat_e.html. Accessed November 9, 2013.

23. Fann JI, Caffarelli AD, Georgette G, Howard SK, Gaba DM, Youngblood P, et al. Improvement in coronary anastomosis with cardiac surgery simulation. J Thorac Cardiovasc Surg. 2008;136:1486-91

24. Fann JI, Calhoon JH, Carpenter AJ, Merrill WH, Brown JW, Poston RS, et al. Simulation in coronary artery anastomosis early in cardiothoracic surgical residency training: the Boot Camp experience. J Thorac Cardiovasc Surg. 2010;139:1275-81.

25. Nakao M, Oyama H, Komori M, Matsuda T, Sakaguchi G, Komeda M, et al. Haptic reproduction and interactive visualization of a beating heart for cardiovascular surgery simulation. Int J Med Inform. 2002;68:155-63.

26. Berlage T, Schmitgen A, Schmitz C, Welz A. Simulation and planning of minimally invasive coronary artery bypass surgery. Int Congr Ser. 2001;1230:68-72.

27. Joyce DL, Dhillon TS, Caffarelli AD, Joyce DD, Tsirigotis DN, Burdon TA, et al Simulation and skills training in mitral valve surgery. J Thorac Cardiovasc Surg. 2011;141:107-12.

28. Tavlasoglu M, Jahollari A, Amrahov A, Sahin MA. An instrument facilitates mitral valve repair training at home. Eur J Cardiothorac Surg. 2012;41:940-1.

29. The Chamberlain Group. Case study: heart case. Available at: http://www. thecgroup.com/process/case-study-heart-case. Accessed November 11, 2011.

30. Solomon B, Bizekis C, Dellis SL, Donington JS, Oliker A, Balsam LB, et al. Simulating video-assisted thoracoscopic lobectomy: a virtual reality cognitive task simulation. J Thorac Cardiovasc Surg. 2011;141:249-55.

31. Iwasaki A, Moriyama S, Shirakusa T. New trainer for video-assisted thoracic surgery lobectomy. Thorac Cardiovasc Surg. 2008;56:32-6.
32. Tesche LJ, Feins RH, Dedmon MM, Newton KN, Egan TM, Haithcock BE, et al. Simulation experience enhances medical students' interest in cardiothoracic surgery. Ann Thorac Surg. 2010;90:1967-74.

33. Fann JI, Feins RH, Hicks GL Jr, Nesbitt JC, Hammon JW, Crawford FA Jr. Evaluation of simulation training in cardiothoracic surgery: the Senior Tour perspective. J Thorac Cardiovasc Surg. 2012;143:264-72.

34. Meyerson SL, LoCascio F, Balderson SS, D'Amico TA. An inexpensive, reproducible tissue simulator for teaching thoracoscopic lobectomy. Ann Thorac Surg. 2010;89:594-7

35. Carter YM, Marshall MB. Open lobectomy simulator is an effective tool for teaching thoracic surgical skills. Ann Thorac Surg. 2009;87:1546-51.

36. Davoudi M, Colt HG. Bronchoscopy simulation: a brief review. Adv Health Sci Educ Theory Pract. 2009;14:287-96.

37. Desilets DJ, Banerjee S, Barth BA, Kaul V, Kethu SR, Pedrosa MC, et al. Endoscopic simulators. Gastrointest Endosc. 2011;73:861-7.

38. Chen JS, Hsu HH, Lai IR, Tai HC, Lai HS, Lee YC, et al. Validation of a computer-based bronchoscopy simulator developed in Taiwan. J Formos Med Assoc. 2006; 105:569-76

39. Bro-Nielsen M, Tasto JL, Cunningham R, Merril GL. PreOp endoscopic simulator: a PC-based immersive training system for bronchoscopy. Stud Health Technol Inform. 1999;62:76-82

40. Miceli L, Cecconi M, Tripi G, Zauli M, Della Rocca G. Evaluation of new laryngoscope blade for tracheal intubation, Truview EVO2: a manikin study. Eur J Anaesthesiol. 2008;25:446-9.

41. Di Domenico S, Simonassi C, Chessa L. Inexpensive anatomical trainer for bronchoscopy. Interact Cardiovasc Thorac Surg. 2007;6:567-9.

42. Immersion Corporation. Immersion Corporation reports first quarter 2009 results. Available at: http://ir.immersion.com/releasedetail.cfm?releaseid=381560. Accessed November 11, 2011.

43. Bar-Meir S. A new endoscopic simulator. Endoscopy. 2000;32:898-900

44. Neumann M, Mayer G, Ell C, Felzmann T, Reingruber B, Horbach T, et al. The Erlangen Endo-Trainer: life-like simulation for diagnostic and interventional endoscopic retrograde cholangiography. Endoscopy. 2000;32:906-10.

45. Choi C, Han H, An B, Kim J. Development of a surgical simulator for laparoscopic esophageal procedures. Conf Proc IEEE Eng Med Biol Soc. 2006;1:819-22.

46. Trehan K, Zhou X, Tang Y, Petrisor D, Kemp C, Yang S. THE GooseMan: a simulator for transhiatal esophagectomy. J Thorac Cardiovasc Surg. 2013;145:1450-2.

47. Lake CL. Simulation in cardiology and cardiothoracic and vascular surgery Semin Cardiothorac Vasc Anesth. 2005;9:325-33.

48. Satava RM. Historical review of surgical simulation-a personal perspective World J Surg. 2008;32:141-8.

49. Simulation. Chest drain simulator. Available at: http://www.simulution.com/ shop-online/whole-body-manikins/emergency-medicine/chest-drain-simulator\# producttabs-1. Accessed November 11, 2011.

50. Carter YM, Wilson BM, Hall E, Marshall MB. Multipurpose simulator for technical skill development in thoracic surgery. J Surg Res. 2010;163:186-91.

51. Marshall MB, Wilson BM, Carter YM. Thoracic surgery skill proficiency with chest wall tumor simulator. J Surg Res. 2012;174:250-6.

52. Naicker TR, Hughes EA, McLeod DT. Validation of a novel resin-porcine thorax model for chest drain insertion training. Clin Med. 2012;12:49-52.

53. Roguin A, Beyar R. Real case virtual reality training prior to carotid artery stenting. Catheter Cardiovasc Interv. 2010;75:279-82.

54. Passman MA, Fleser PS, Dattilo JB, Guzman RJ, Naslund TC. Should simulatorbased endovascular training be integrated into general surgery residency programs? Am J Surg. 2007;194:212-9.

55. Dawson DL. Training in carotid artery stenting: do carotid simulation systems really help? Vascular. 2006;14:256-63.

56. Cristancho S, Moussa F, Dubrowski A. Simulation-augmented training program for off-pump coronary artery bypass surgery: developing and validating performance assessments. Surgery. 2012;151:785-95.

57. Konge L, Lehnert P, Hansen HJ, Petersen RH, Ringsted C. Reliable and valid assessment of performance in thoracoscopy. Surg Endosc. 2012;26:1624-8.

58. Tong BC, Gustafson MR, Balderson SS, D’Amico TA, Meyerson SL. Validation of a thoracoscopic lobectomy simulator. Eur J Cardiothorac Surg. 2012;42:364-9.

59. Price J, Naik V, Boodhwani M, Brandys T, Hendry P, Lam BK. A randomized evaluation of simulation training on performance of vascular anastomosis on a high-fidelity in vivo model: the role of deliberate practice. $J$ Thorac Cardiovasc Surg. 2011;142:496-503 

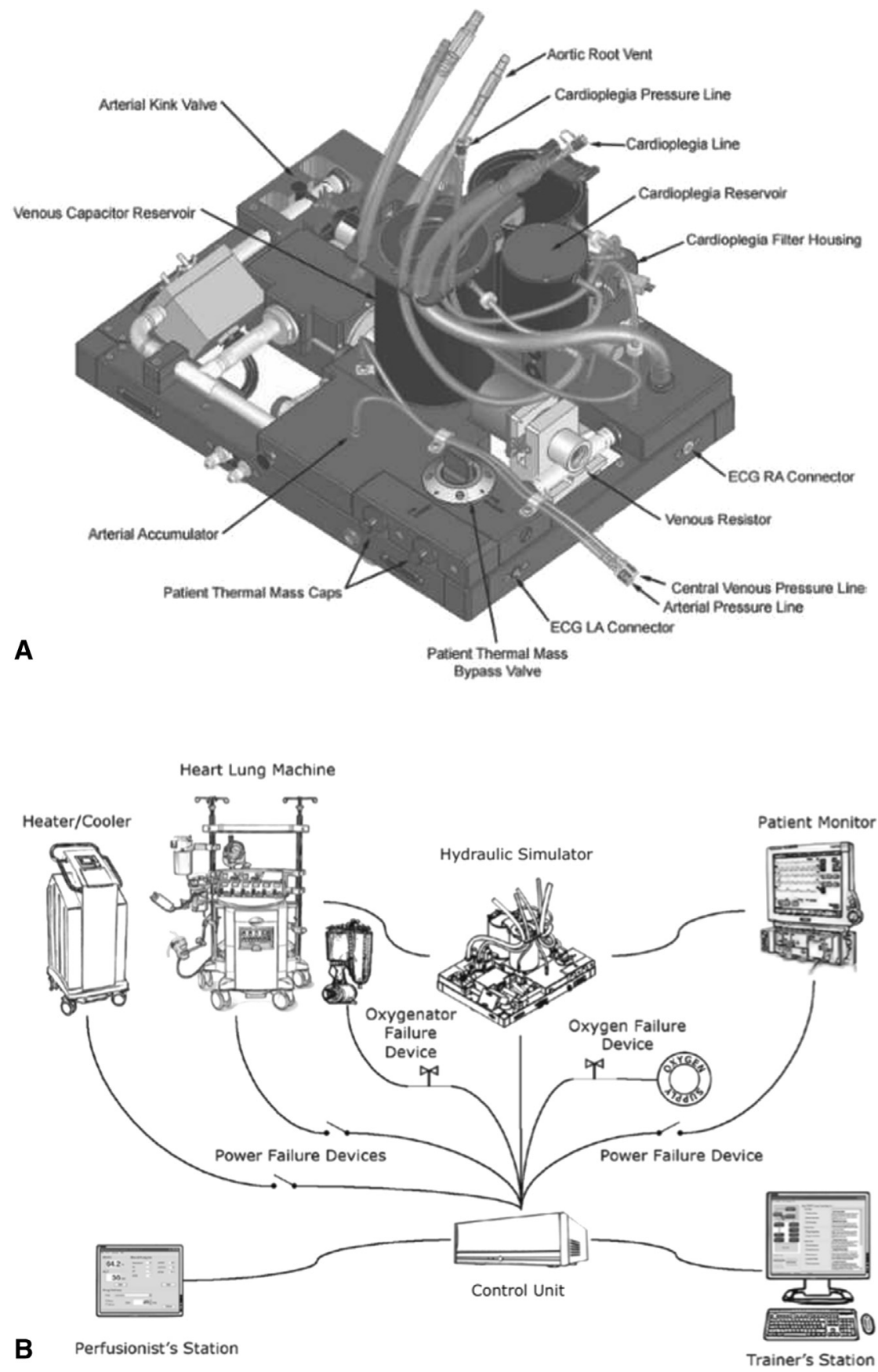

FIGURE E1. The Orpheus Cardiopulmonary Bypass System (ULCO Technologies, Marrickville, Australia). A, Hydraulic simulator. B, Complete setup incorporating the hydraulic simulator along with the other components of a simulated OR. ECG, Electrocardiogram; $L A$, left atrium; $R A$, right atrium. Reprinted with permission from Morris RW, Pybus DA. "Orpheus" cardiopulmonary bypass simulation system. J Extra Corpor Technol. 2007;39:228-33, and the Orpheus Corporation. 


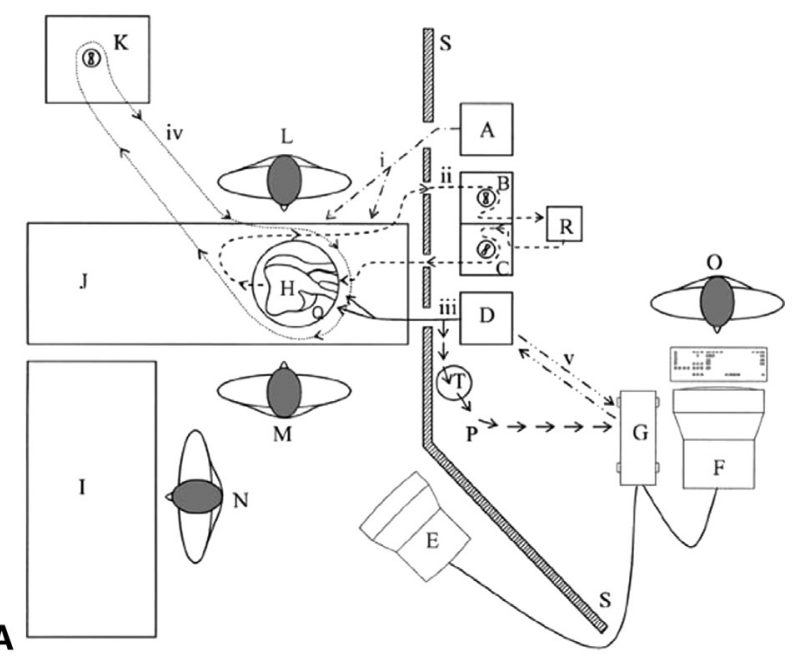

B

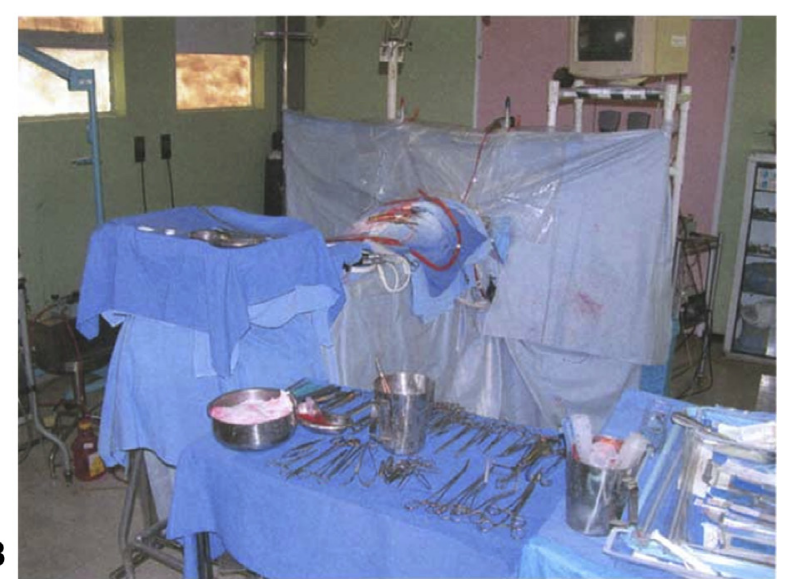

FIGURE E2. The Ramphal Cardiac Surgical Simulator. A, Schematic diagram: $A$ represents pneumatic pulmonary pump. $B$ represents hydraulic suction pump. $C$ represents hydraulic coronary pump. $D$ represents pneumatic ventricular pump. $E$ represents simulated intraoperative vital signs monitor. $F$ represents control monitor. $G$ represents central processing unit. $H$ represents porcine heart. $I$ represents instrument table. $J$ represents operation bed with simulated patient. $K$ represents hydraulic pump for mock bypass circuit. $L$ represents surgical trainee. $M$ represents supervising surgeon. $N$ represents scrub nurse. $O$ represents simulation operator. $P$ represents pressure feedback loop. $Q$ represents pericardial cavity. $R$ represents fluid reservoir. $S$ represents screen. $T$ represents transducer: $i$ represents tubing to right and left simulated lungs; $i i$ represents tubing circuit from pericardial suction to coronary perfusion; iii represents tubing from ventricular pump to intraventricular balloons; iv represents tubing for mock bypass circuit (precannulation); $v$ represents serial connection between ventricular pump and central processing unit. B, Actual setup of the Ramphal Cardiac Surgery Simulator. Reprinted with permission from Ramphal PS, Coore DN, Craven MP, Forbes NF, Newman SM, Coye AA, et al. A high fidelity tissue-based cardiac surgical simulator. Eur $J$ Cardiothorac Surg. 2005;27:910-6. 